\title{
Microfluidic Biosensor Based on Microwave Substrate-Integrated Waveguide Cavity Resonator
}

\author{
Ahmed Salim, ${ }^{1}$ Sung-Hwan Kim, ${ }^{2}$ Joong Yull Park, ${ }^{2}$ and Sungjoon Lim $\mathbb{D}^{1}$ \\ ${ }^{1}$ School of Electrical and Electronics Engineering, College of Engineering, Chung-Ang University, 84 Heukseok-ro, Dongjak-gu, \\ Seoul 06974, Republic of Korea \\ ${ }^{2}$ School of Mechanical Engineering, College of Engineering, Chung-Ang University, 84 Heukseok-ro, Dongjak-gu, \\ Seoul 06974, Republic of Korea \\ Correspondence should be addressed to Sungjoon Lim; sungjoon@cau.ac.kr
}

Received 11 July 2017; Revised 26 October 2017; Accepted 29 November 2017; Published 1 February 2018

Academic Editor: Romeo Bernini

Copyright (C) 2018 Ahmed Salim et al. This is an open access article distributed under the Creative Commons Attribution License, which permits unrestricted use, distribution, and reproduction in any medium, provided the original work is properly cited.

\begin{abstract}
A microfluidic biosensor is proposed using a microwave substrate-integrated waveguide (SIW) cavity resonator. The main objectives of this noninvasive biosensor are to detect and analyze biomaterial using tiny liquid volumes $(3 \mu \mathrm{L})$. The sensing mechanism of our proposed biosensor relies on the dielectric perturbation phenomenon of biomaterial under test, which causes a change in resonance frequency and return loss (amplitude). First, an SIW cavity is realized on a Rogers RT/Duroid 5870 substrate. Then, a microwell made from polydimethylsiloxane (PDMS) material is loaded on the SIW cavity to observe the perturbation phenomenon. The microwell is filled with phosphate-buffered saline (PBS) solution (reference biological medium). To demonstrate the sensing behavior, the fibroblast (FB) cells from the lungs of a human male subject are analyzed and oneport S-parameters are measured. The resonance frequency of the structure with FB cells is observed to be $13.48 \mathrm{GHz}$. The reproducibility and repeatability of our proposed biosensor are successfully demonstrated through full-wave simulations and measurements. The resonance frequency of the FB-loaded microwell showed a shift of $170 \mathrm{MHz}$ and $20 \mathrm{MHz}$, when compared to those of empty and PBS-loaded microwells. Its analytical limit of detection is $213 \mathrm{cells} / \mu \mathrm{L}$. Our proposed biosensor is noncontact and reliable. Furthermore, it is miniaturized, inexpensive, and fabricated using simple- and easy-design processes.
\end{abstract}

\section{Introduction}

Miniaturized sensors can be integrated with other components/system and can be cost effective, and mass production is an essential step to realize point-of-care testing [1]. They not only reduce cost by avoiding expensive equipment but also demand less maintenance that is required in the case of conventional testing laboratories equipped with bulky machinery. Miniaturization is also important to reduce the volume of samples required for testing. A biosensor should provide small-form factor, portability, and real-time and accurate analyses of human cells [2]. Thus, the use of lowcost miniaturized biosensors proliferates from expert users to patients themselves [3].

State-of-the-art biosensing devices have been realized using three key detection modalities-electrical, optical, and mechanical [3]. Electrochemical biosensors predominantly use enzymes, and they can be classified into amperometric, potentiometric, or conductometric sensors. As the names imply, the responses of these sensors appear as changes in the associated electrolytic current, voltage, or resistance [4]. Integrated optical waveguide technologies have been used to realize biosensors, for instance, the evanescent wave propagation mechanism, which measures a change in the refractive index or guided wavelength. The evanescent field detection enables highly sensitive, label-free, selective detection if proper bioreceptors and immobilization protocols are employed [5]. However, higher cost and complicated fabrication processes limit the scope of these biosensors [6].

Integration of microfluidics and microelectronics has led to an innovative and pragmatic approach-microwave-based biosensing at the cellular level [7]. The reduction in some 
fluid samples required for testing and biochemical analysis at microwave frequencies provides some inherent advantages such as reduction in measurement time and reusability [8]. Passive RF biosensors utilize either metamaterial elements such as ring resonators or rectangular/cylindrical cavity resonators $[9,10]$. A microfluidic sensor based on a coplanar waveguide transmission line, to characterize the broadband complex permittivity, cell sorting, and quantification of biological media is proposed in [11]. The emergence of dielectric spectroscopy [12] and living cell suspension analysis using microwave biosensing was a further development [7]. Recently, noninvasive detection of even a single biological cell, using RF biosensors, has emerged as an inexpensive, miniaturized, biocompatible, and label-free (contrary to cytometry) technique [13]. In general, label-free detection, compact size, and low cost are the attractive features provided by RF biosensors. Microelectromechanical system (MEMS) fabrication processes have been realized for enhanced sensitivity and further miniaturization in RF biosensors. For instance, in [14], even 50 cells of HepaG2 (a human cancer cell) could be detected with an RF biosensor (size $2.4 \mathrm{~mm} \times 2.4 \mathrm{~mm}$ ) using a planar LC resonant circuit. In [15], an MEMS-based glucose biosensor using a rectangular meandered-line resonator was proposed, with a size of only $2 \mathrm{~mm} \times 1.8 \mathrm{~mm}$. Nevertheless, micro-nano-sized RF biosensors require a more complex and detailed measurement system, for instance, RF probe station [9]. Furthermore, unwieldy and expensive measurement equipment makes them highly unattractive.

Since the discovery of influenza A virus infection (1933), influenza B virus isolation (1936), and influenza C virus isolation (1950), the detection and bioanalysis of fibroblast cells have become vibrant [16]. The MRC-5 cell line provides the advantage of being able to detect influenza virus during the early stages of possible epidemic spread [16]. The study of properties of the virus characteristics ultimately led to the development of vaccination [16]. As another example, the cell size, cell cycle, shape, and other observable characteristics of human lung fibroblasts have been explored in 1998 [17]. According to the 2017 fact sheet of World Health Organization (WHO), hepatitis B caused 887,000 deaths in 2015 and 257 million people have been infected by life-threatening hepatitis B virus (activated state) that is an alarming situation. Aside from its beneficial detection, the MRC- 5 cell line has been widely available/accessible in clinics and research laboratories [16].

Substrate-integrated waveguide (SIW) is a promising technology to realize sensing applications because of its planar nature and ability to render the advantages of conventional rectangular waveguides, such as low-loss (radiation and leakage), high-Q-factor, and higher power handling capability [18]. Its planar structure allows straightforward integration of active circuits and passive components. It offers a low-cost, compact design with an easy fabrication process. The abundance of high electric field energy concentrated in the center of the SIW cavity has been exploited in a variety of applications such as chemical sensing [19], crack detection [20], and tuning purposes [21]. In [22, 23], SIW cavity is proposed to sense liquid methanol (at $60 \mathrm{GHz}$ ) and liquid isopropanol (at $90 \mathrm{GHz}$ ), respectively. The LTCC technology was employed to fabricate stacked structures, and the size of the device was in a few millimeters' dimension. SIWs were also utilized to sense various chemicals and extract dielectric constants [24, 25]. A few SIW cavity resonators have been proposed as chemical sensors, but only one of them has been experimentally demonstrated as a biosensing device [26]. They discriminated the alive and dead cells of Chinese hamster ovarian cells using an SIW structure. The measurement curves of resonance frequency and quality factor for both cases (alive cells and dead cells) were compared to draw the conclusions [26]. The novelty of our proposed research is that this is the first time that the detection of fibroblast cells is demonstrated using the SIW cavity-based RF biosensor. Secondly, excellent performance and other advantages (e.g., compact design, low cost, and rapid detection) of microwave-assisted microfluidic biosensor, as discussed in the previous paragraphs, make it an attractive choice to detect and analyze the fibroblast cells.

The choice of high frequency brings forth an enhanced interaction of electromagnetic waves because biocell dimension becomes comparable with this wavelength [13]. Highfrequency structures are obviously smaller; in addition, microwaves are nonionizing as compared to X-rays [1]. Optical and microwave frequencies penetrate in the cell membrane and possibly in the cytoplasm [13], and it is possible to peep into an individual cell [7]. Keeping in view these perspectives, we deemed gigahertz frequency $(13-14 \mathrm{GHz})$ to analyze target biomaterial.

In this paper, a microfluidic biosensor is realized using an SIW cavity resonator. The proposed sensor can detect fibroblast (FB) cells using the frequency shift in the microfluidically loaded SIW cavity. Our proposed sensor is noninvasive and provides additional benefits such as miniaturization, low cost, and easy fabrication process. Tiny volumes of biomaterials are required to test and analyze the proposed sensor. It avoids any reagent, lubricator, label, or immobilization protocol. Lightweight, rapid detection, and fast recovery time are its further advantages. The first part of the sensor design consists of the fabrication of a rectangular SIW cavity resonator. In the second part, a cup-shaped microfluidic container (microwell) is conceived and fabricated using polydimethylsiloxane (PDMS). The microwell is designed to keep the biomaterial intact while maintaining its noncontact, reusable, and reliable properties. Besides, it has a simple design that is replaceable and offers meager cost. The overall structure size and the cost are reduced.

The design guidelines for the SIW cavity resonator, microwell, cell preparation, and spheroid culture are explained. The performance of the proposed sensor is demonstrated through full-wave simulations and S-parameter measurements.

\section{Sensor Design}

2.1. SIW Cavity Design. The layout of an SIW cavity resonator fed by a combination of a microstrip line, a quarterwave stub, and an inset feed is shown in Figure 1. A 


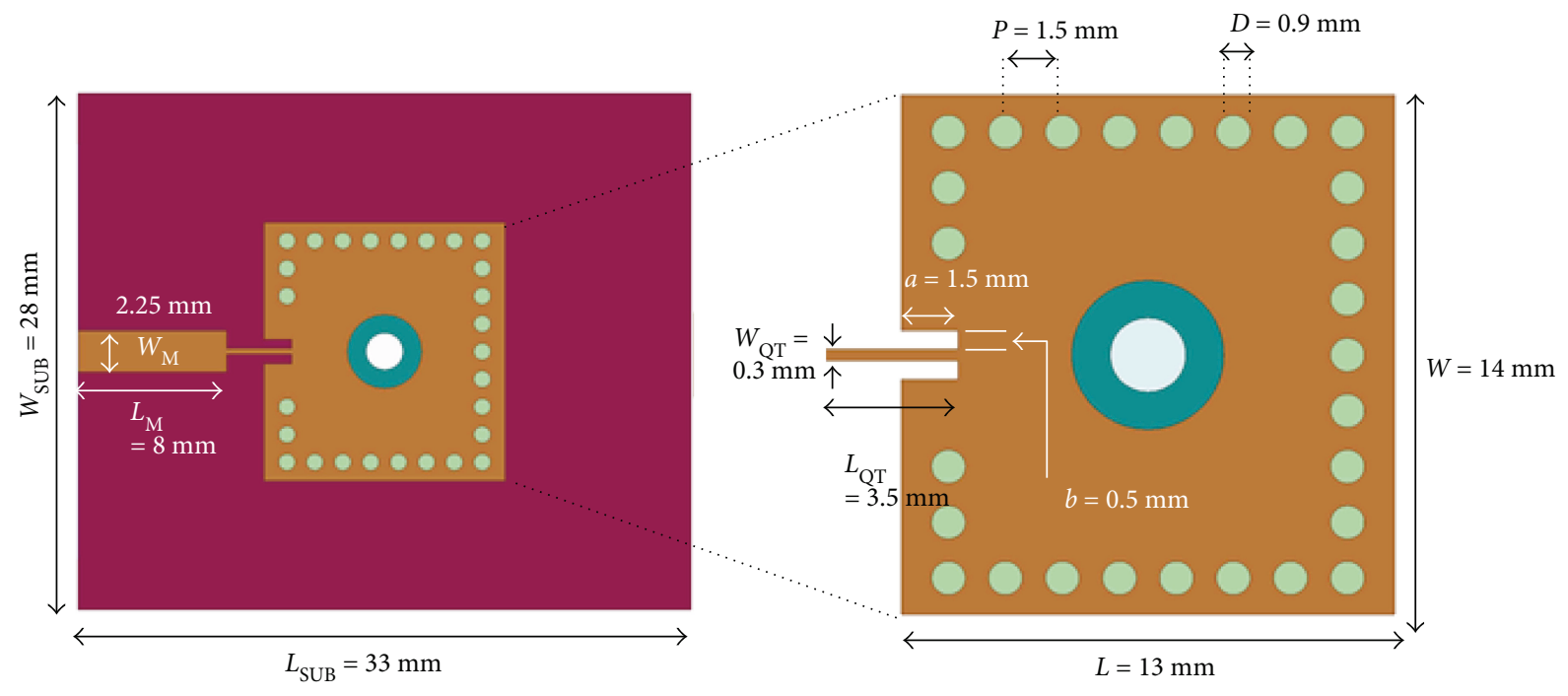

(a)

(b)

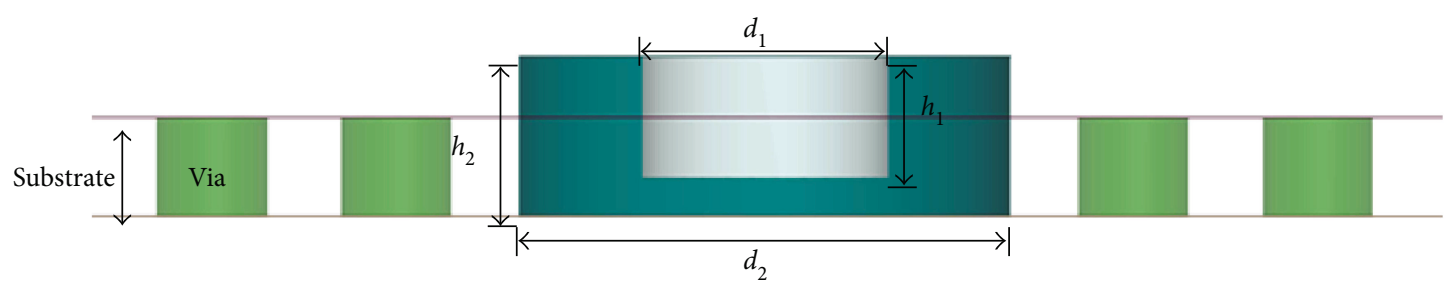

(c)

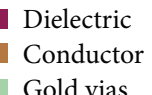

PDMS

Biomaterial

FIgURE 1: (a) Top view of the SIW cavity resonator proposed as a microfluidic biosensor. (b) Inset view depicting a patch, gold vias, and PDMS-based microwell. (c) Cross-sectional view of the SIW cavity resonator demonstrating geometry of the cup-shaped microwell.

Rogers RT/Duroid 5870 (Rogers Corporation Inc., Chandler, AZ, USA) (substrate thickness $h_{\mathrm{SUB}}=0.8 \mathrm{~mm}$, dielectric constant $=2.33$, and loss tangent $=0.0012$ ) is used to realize the design. When the thickness of the SIW cavity $(h)$ is much less than the width $(W)$ and length $(L)$, the resonance frequency $\left(f_{\mathrm{mn}}\right)$ of the proposed SIW cavity resonator can be defined as follows:

$$
f_{\mathrm{mn}}=\frac{1}{2 \pi \sqrt{\mu \varepsilon}} \sqrt{\left(\frac{m \pi}{W_{\mathrm{eff}}}\right)^{2}+\left(\frac{n \pi}{L_{\mathrm{eff}}}\right)^{2}}
$$

where $\varepsilon, \mu, W_{\text {eff }}$, and $L_{\text {eff }}$ are the permittivity, permeability of the dielectric material, effective width, and effective length of the SIW structure, respectively [19]. The indices $m$ and $n$ are integers, used to characterize the mode of the SIW structure.

First, a rectangular patch is designed, and then, arrays of metallic vias are realized near the boundaries of the patch. They connect the top (metallic pattern) and bottom (ground plane) surfaces. The magnetic sidewalls confine the electric field inside the rectangular patch, and that electric field can be utilized for dielectric perturbation. A good dielectric material is necessary to minimize the dielectric loss. The diameter of each via $(D)$ and the center-to-center spacing between any two consecutive vias (pitch $(P)$ ) are the design parameters that determine the SIW performance and are given below:

$$
\begin{aligned}
& D<\frac{\lambda_{\mathrm{g}}}{5}, \\
& P<2 D,
\end{aligned}
$$

where $\lambda_{\mathrm{g}}$ represents the guided wavelength in the structure [27]. To reduce the leakage losses between adjacent vias, $P$ should be maintained low [27]. Furthermore, $D$ affects the return loss. The sidewall vias create a magnetic wall near the boundary of the rectangular patch. Thus, all the electric field energy remains at the center of the SIW cavity, which can be utilized for sensing applications [20]. After considering the reductions in the leakage and radiation losses, the values of $D$ and $P$ are chosen as $0.9 \mathrm{~mm}$ and $1.5 \mathrm{~mm}$, respectively. The heights of all vias are the same as the substrate thickness $\left(h_{\mathrm{SUB}}=0.8 \mathrm{~mm}\right)$. The size of the rectangular patch $(L \times W)$ is chosen as $14 \mathrm{~mm} \times 13 \mathrm{~mm}$, to excite the SIW structure (without the center hole) in the $\mathrm{TE}_{110}$ as the dominant mode, and it resonates at $12.46 \mathrm{GHz}$. The 


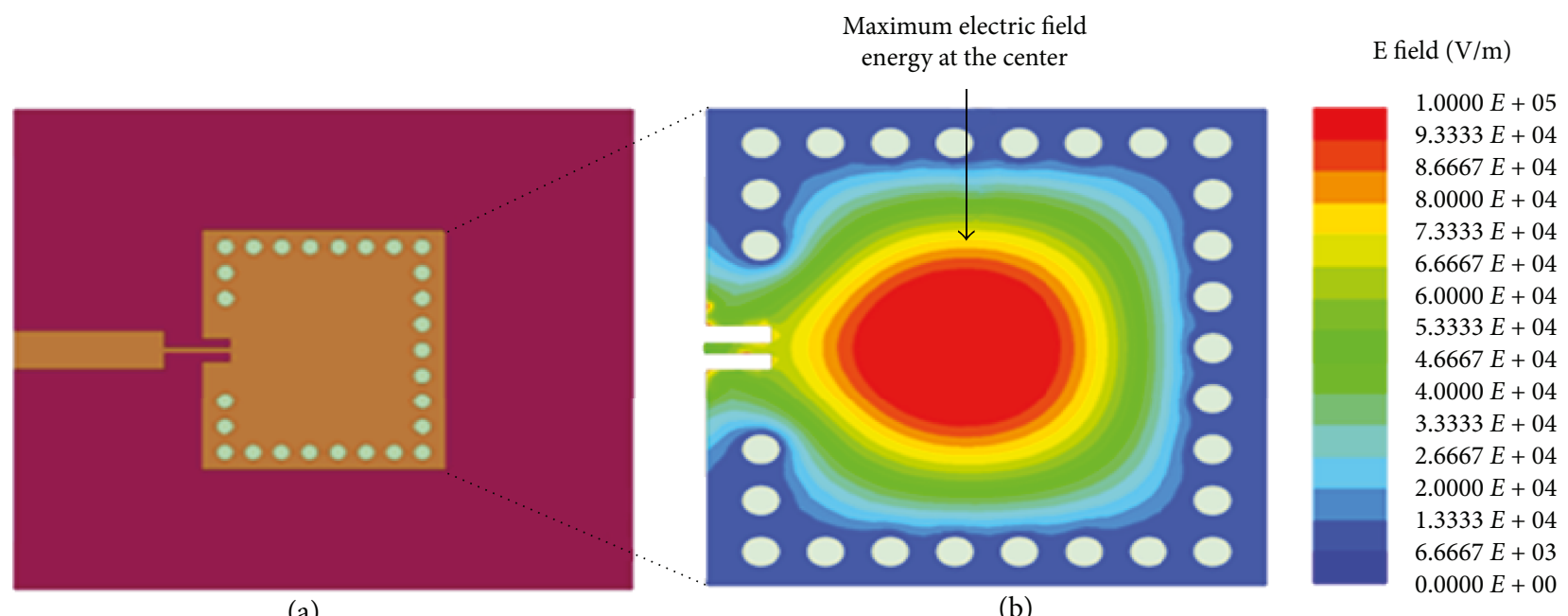

(a)

(b)

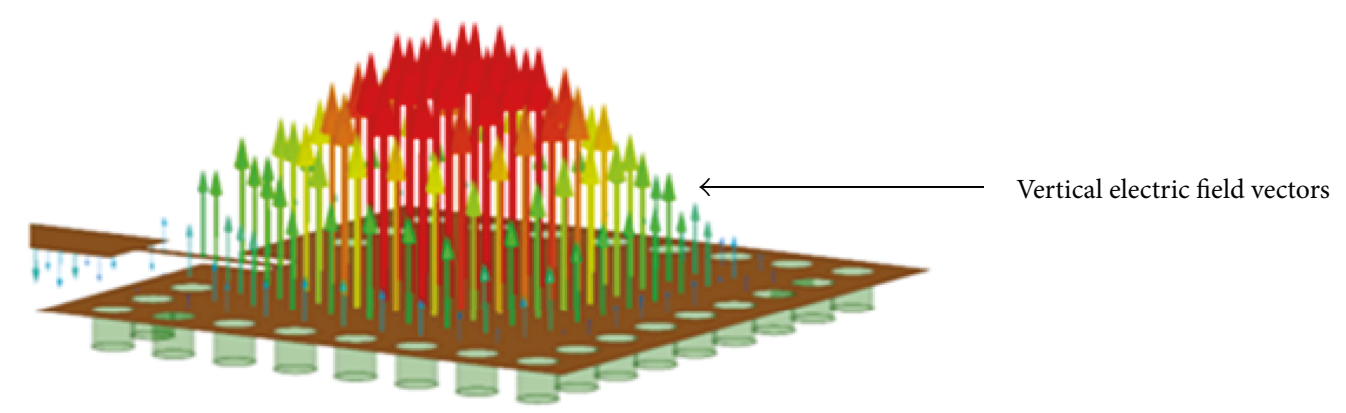

(c)

FIgURE 2: (a) Top view of the SIW cavity resonator (without a hole in the center). (b) Electric field magnitude distribution at a resonance frequency of $12.46 \mathrm{GHz}$; the highest energy is concentrated at the center of SIW cavity. (c) Vertical electric field vector distribution in the SIW cavity.

feed line is a combination of a microstrip line, a quarterwave stub, and an inset feed. The width of the microstrip line $\left(W_{\mathrm{M}}=2.25 \mathrm{~mm}\right)$ is designed for $50 \Omega$ compatibility with a SubMiniature version A (SMA) connector. The length and width of the quarter-wave transformer $\left(L_{\mathrm{QT}} \times W_{\mathrm{OT}}\right)$ are $3.5 \mathrm{~mm}$ and $0.3 \mathrm{~mm}$, respectively, for a good impedance match between the microstrip line and SIW structure. The length and width of the inset feed $(a \times b)$ are $1.5 \mathrm{~mm}$ and $0.5 \mathrm{~mm}$, respectively. The electrical size of our proposed biosensor is $2.27 \lambda_{\mathrm{g}} \times 1.93 \lambda_{\mathrm{g}}$.

2.2. Microwell Design. The microwell is designed after considering the maximum frequency shift and fabrication limit, and it is designed to preserve the noncontact feature of the sensor. The SIW structure (without hole) and its electric field distribution (magnitude) are shown in Figures 2(a) and 2(b). Figure 2(c) shows the electric field vector distributions. To maximize the electric field perturbation, the microwell must be loaded at the position of the strongest electric field in the structure. The maximum electric field magnitude (confirmed from the color code) resides at the center of the SIW cavity. Therefore, it is the best position to where the microwell be loaded. The vertical distribution of the electric field vector (Figure 2(c)) suggests that a cylindrical/cup-shaped microcontainer loaded at the center of the SIW cavity would be the best option because it would allow the maximum electric field lines to pass through the liquid-filled microcontainer that makes the interaction with the electric field lines even more strong. A single orifice would be convenient to inject/ remove the biomaterial from the microwell. It also eliminates the need for a separate inlet and outlet and thus simplifies the design and fabrication of our proposed microwell. When the FB cells replace the phosphate-buffered saline (PBS) solution inside the microwell, the effective permittivity changes and the resonance frequency of the SIW cavity resonator switches. To achieve the best performance (maximum frequency shift), while consuming minimum biomaterial volumes, different diameters and thicknesses of the PDMS and microwell are investigated. When diameter $d_{2}$ is increased, capacitance $\left(C_{\text {eff }}\right)$ is decreased and the resonance frequency is increased, as shown in Figure 3(a). For a considerable frequency shift, we calculate the diameter $\left(d_{2}\right)$ of the loaded PDMS to be $4 \mathrm{~mm}$.

More fluid volumes cause more shift in the resonance frequency, as can be expected. A significant frequency shift is observed when the lower end of the microwell container coincides with the ground plane. However, this would either require attachment of an adhesive bonding film on the bottom of the microwell, which implies additional losses, or lose its noncontact feature in which case the liquid directly 


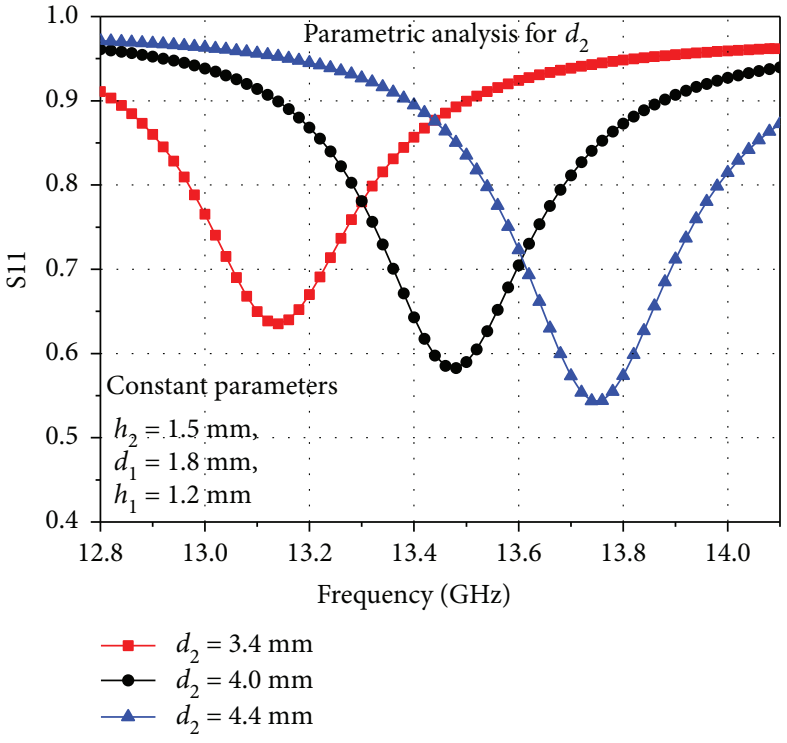

(a)

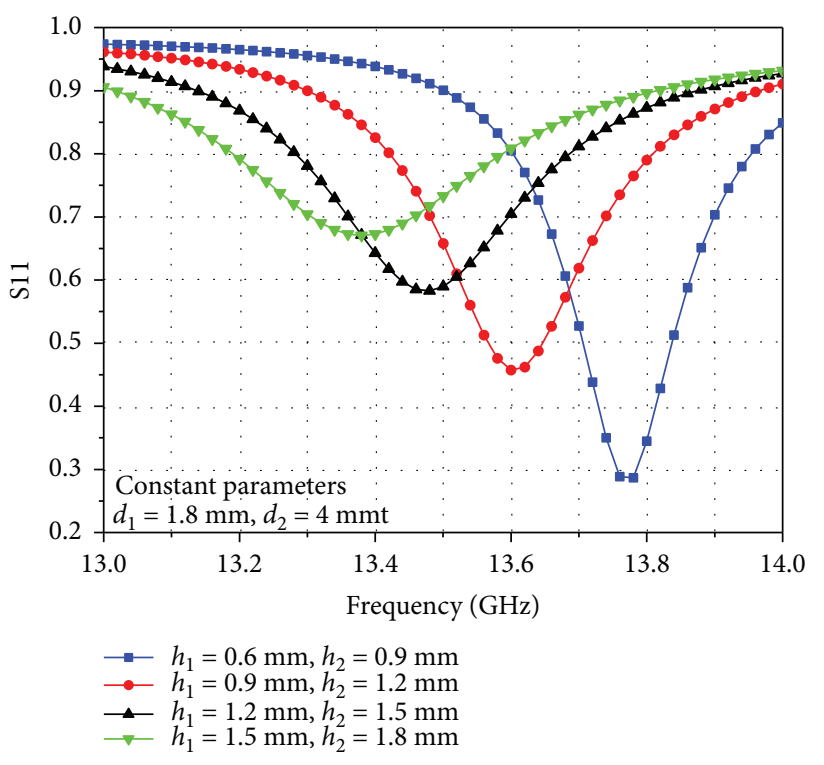

(b)

FIgURE 3: Simulated S11 of our proposed biosensor at different (a) diameters of PDMS $d_{2}$ and (b) height of PDMS $\left(h_{2}\right)$.

TABLE 1: Design parameters of the SIW cavity resonator proposed as a biosensor.

\begin{tabular}{lccccccc}
\hline Parameter & Dimension $(\mathrm{mm})$ & Parameter & Dimension $(\mathrm{mm})$ & Parameter & Dimension $(\mathrm{mm})$ & Parameter & Dimension $(\mathrm{mm})$ \\
\hline$W_{\mathrm{SUB}}$ & 28 & $L_{\mathrm{M}}$ & 8 & $L_{\mathrm{QT}}$ & 3.5 & $d_{1}$ & 1.8 \\
$L_{\mathrm{SUB}}$ & 33 & $W_{\mathrm{M}}$ & 2.25 & $W_{\mathrm{QT}}$ & 0.3 & $d_{2}$ & 4 \\
$W$ & 14 & $a$ & 1.5 & $h_{1}$ & 1.2 & $D$ & 0.9 \\
$L$ & 13 & $b$ & 0.5 & $h_{2}$ & 1.5 & $P$ & 1.5 \\
\hline
\end{tabular}

touches the bottom ground. To mitigate these issues, the shift in the resonance frequency is compromised a little and the lower end of the microwell is envisaged slightly above the ground plane. By doing this, the sensor remains noncontact and potentially safe. In Figure 3(b), height of PDMS $\left(h_{2}\right)$ is investigated in relation with $h_{1}$ (thickness of $h_{1}$ ), while keeping $d_{1}$ and $d_{2}$ as constant parameters. An optimum geometry $\left(d_{1} \times h_{1}\right)$ of $1.8 \mathrm{~mm} \times 1.2 \mathrm{~mm}$ is selected for the cupshaped microcontainer based on the simulation analysis performed using a high-frequency structural simulator ((HFSS) ANSYS Inc., Canonsburg, PA, USA). The thickness $\left(h_{2}\right)$ of the loaded PDMS is found to be $1.5 \mathrm{~mm}$ after considering the already-mentioned parameters. The volume of the optimized microwell $\left(V=\pi r_{1}^{2} h_{1}\right)$ is $3 \mathrm{~mm}^{3}$, which is equivalent to containing $3 \mu \mathrm{L}$ of fluid. All design parameters of our proposed biosensor are mentioned in Table 1.

\section{Sensitivity Analysis}

The biosensor presented in Figure 1 provides a response in terms of a change in the resonance frequency. Liquids with different permittivity values are loaded in the microwell, the electric field is perturbed, and the resonance frequency is changed. The effective capacitance changes, which produces a considerable shift in the return loss and in the resonance frequency, depending on the relative change in the permittivity of the fluid. In order to assess the sensitivity, the resonance frequencies of the unloaded sensor (empty microwell) and the PBS-filled microwell $\left(f_{\text {air }}\right.$ and $\left.f_{\mathrm{PBS}}\right)$ are simulated. Note that PBS is a water-based salt solution that prevents cell damage by providing osmolarity of human body fluid and widely used in practical cell experiments. It is observed that a relative change in the resonance frequency $\left(\Delta f_{\text {res }}\right)$ is linearly related to the corresponding relative change in the permittivity $(\Delta \varepsilon)$. The sensitivity $S$ of our proposed biosensor is defined as

$$
S=\frac{\Delta f_{\mathrm{res}}}{\Delta \varepsilon}=\left|\frac{f_{\mathrm{air}}-f_{\mathrm{PBS}}}{\varepsilon_{\mathrm{air}}-\varepsilon_{\mathrm{PBS}}}\right|,
$$

where $\varepsilon_{\text {air }}$ is the permittivity of free space and $\varepsilon_{\mathrm{PBS}}$ is the permittivity of the PBS solution. PBS is a water-based salt solution, commonly used as a buffer to store biomaterials. The values of the real $\left(\varepsilon^{\prime}\right)$ and imaginary parts $\left(\varepsilon^{\prime \prime}\right)$ of the complex permittivity of water at $13 \mathrm{GHz}$ are 55.4 and 33.8 , respectively [28]. Thus, the dielectric constant $\left(\varepsilon_{r}\right)$ and loss tangent $\left(\tan \delta=\varepsilon^{\prime \prime} / \varepsilon^{\prime}\right)$ of the PBS solution at $13 \mathrm{GHz}$ are simulated to be 55 and 0.6 , respectively. The tissue and cells contain much water, and the tissue water is identical to normal water except for a negligible variation where proteins exist as reported in [29] while explaining the $\gamma$-dispersion effect. Because water constitutes a big portion of the FB cells, we fairly assume that the value of the real part of the complex permittivity of the FB cells approaches that of water in the 


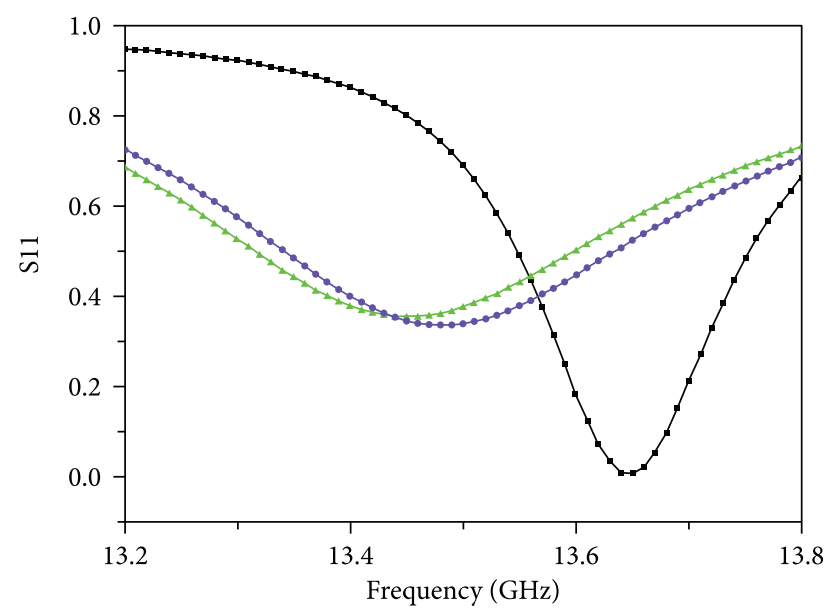

Simulation analysis

- Empty microwell

$\simeq \operatorname{PBS}(3 \mu \mathrm{L})$

$\longrightarrow$ Fibroblast cells $(3 \mu \mathrm{L})$

Figure 4: Simulated return losses of the proposed biosensor using an empty microwell, PBS, and FB cells (all with a $3 \mu \mathrm{L}$ volume).

$\mathrm{GHz}$ regime (nearly $13 \mathrm{GHz}$ ). After considering these notions, the permittivity and loss tangent values of the $\mathrm{FB}$ cells are characterized as 53 and 0.6 , respectively. Two research evidences $[30,31]$ ratify our assumption. Based on the above discussion, we expect the behavior of the FB cells (resonance frequency and return loss magnitude) to be close to that of the PBS solution if the measurements are conducted at the same operating frequency, using the same measurement setup. For full-wave simulation, the dielectric constant and loss tangent of PDMS are set as 2.8 and 0.05 , respectively [32]. The resonance frequency with an empty microwell is $13.65 \mathrm{GHz}$. The resonance frequency switches to 13.48 and $13.46 \mathrm{GHz}$ when the permittivity and loss tangent values of the FB cells and PBS solution are simulated, as shown in Figure 4.

\section{Fabrication}

The proposed biosensor is realized through a three-step process (Figure 5). In the first step, a rectangular patch is etched on top of a Rogers RT/Duroid 5870 substrate using conventional photolithography. A hole (with the same diameter as that of the PDMS size) is drilled in the patch and substrate, as a second step. The gold vias are inserted in the holes to physically connect the patch with the ground. An SMA connector (part number: PAF-S05 Series, $13.27 \mathrm{~mm}$ long, manufactured by GigaLane Co. Ltd.) [33] is connected with the microstrip line. The datasheet provided by the manufacturer asserts that the frequency range of this SMA is $\mathrm{Dc}-18 \mathrm{GHz}$. In the third step, the microwell engraved on the PDMS substrate is accurately aligned at the center of the SIW cavity. The PIPETMAN ${ }^{\circledR}$ Classic kit provided by Gilson Inc. (Middleton, WI, USA) was used for the micropipette.

4.1. Cell Preparation. The FB cells were purchased from the American Type Culture Collection ((ATCC) Manassas, VA,
USA; product number MRC-5 (ATCC ${ }^{\circledR}$ CCL-171TM)). The cells were taken from the lungs of a Caucasian male and were in the frozen form when received. Primary FBs (P1) were expanded up to passage 4 (P4) using cell culture media consisting of low-glucose Dulbecco's modified Eagle's media ((DMEM) Hyclone Laboratories Inc., Logan, UT, USA) containing $1 \%$ antibiotic-antimycotic solution (Hyclone Laboratories Inc.) supplemented with fetal bovine serum ((FBS) Hyclone Laboratories Inc., Logan, UT, USA) at $37^{\circ} \mathrm{C}$ and $5 \% \mathrm{CO}_{2}$ in a humidified incubator. The $\mathrm{FBs}$ were washed using PBS (Hyclone Laboratories Inc., Logan, UT, USA), and the medium was changed every third day. The P4 cells were harvested using Trypsin $0.25 \%$ (1x) solution (Hyclone), to be used in this study.

4.2. Spheroid Culture. To form a spheroid, we used a hemispherical concave microwell array with a diameter of $600 \mu \mathrm{m}$ [34]. The device surface should be further treated to prevent cell attachment. To prevent air bubbles from being trapped inside the hemispherical microwell, the PDMS substrate including the hemispherical surface was sterilized using 70\% ethanol and washed in PBS. Since ethanol can easily flow into the hemispherical microwell (owing to the small contact angle), the bubbles can be easily removed using pipettes. Then, the hemispherical PDMS microarray was treated using 4\% Pluronic F-127 solution (product number P2443; Sigma-Aldrich Corporation, St. Louis, MO, USA) for one day to make a nonadhesive surface (necessary for spheroid formation). Precultured FB cells were prepared in DMEM with a concentration of $1 \times 106$ cells $/ \mathrm{mL}$, and $2 \mathrm{~mL}$ of the cells was suspended in the PDMS substrate. All floating cells inside the DMEM settled to the bottom as well as the hemispherical microwell array within $5 \mathrm{~min}$. The microwell can contain only 2000-3000 cells and the rest of the cells (outside the microwell) needed to be harvested. The contained cell number in a single microwell was calculated after one day. Spheroids were aspirated with a $10 \mu \mathrm{L}$ pipette tip and counted using a hemocytometer. To remove the remaining cells, the receding meniscus mechanism was applied [35]. We slowly aspirated the medium to utilize the surface tension between the medium and air to scrape the cells on the substrate surface using a $1000 \mu \mathrm{L}$ pipette. After harvesting the rest of the cells, a uniform number of cells remained in the microwell. The medium was then refilled with DMEM. Seeded FBs were incubated for three days to form spheroids. To remove such extra cells, the medium was carefully aspirated using a $1000 \mu \mathrm{L}$ pipette. The medium was then refilled on the substrate, and within three days of culture, the cells formed a spheroid in each well. The concentration of the FB cells was around 800 cells $/ \mu \mathrm{L}$ when detection was carried out using our proposed biosensor.

4.3. Cell Fixation. To prevent cell contamination during the experiments, the cell spheroids were fixed. The spheroids formed were fixed in $4 \%$ formaldehyde solution for $24 \mathrm{~h}$ at $4^{\circ} \mathrm{C}$. After fixation, the spheroids were gathered into conical tubes by pipetting using $100 \mu \mathrm{L}$ pipettes. Fixed spheroids were not dissociated by pipetting because of the high gravity arising from the centrifugal process. To increase the spheroid 


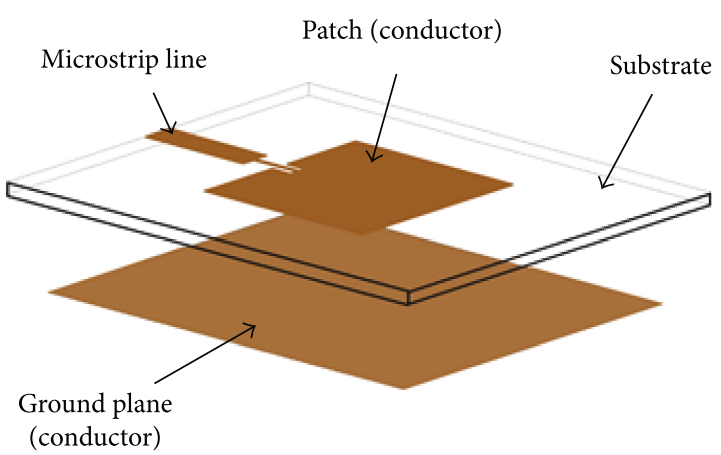

(a)

Biomaterial injected in the cup-shaped microwell through a micropipette

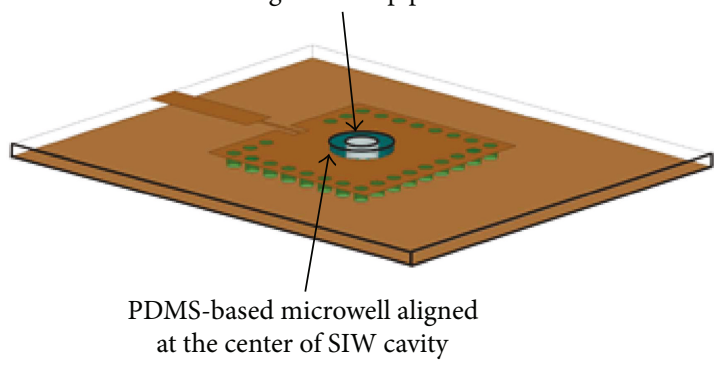

(c)

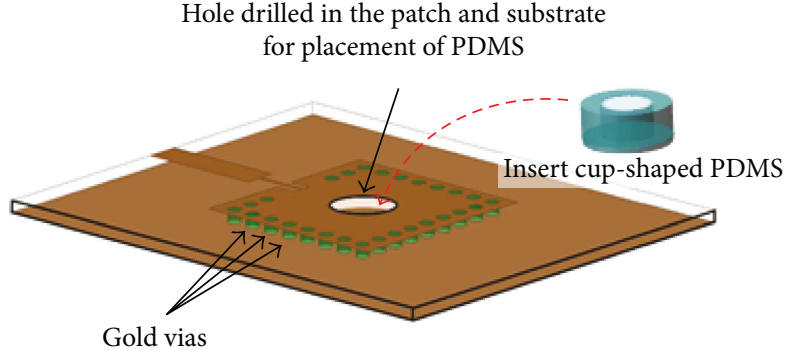

(b)

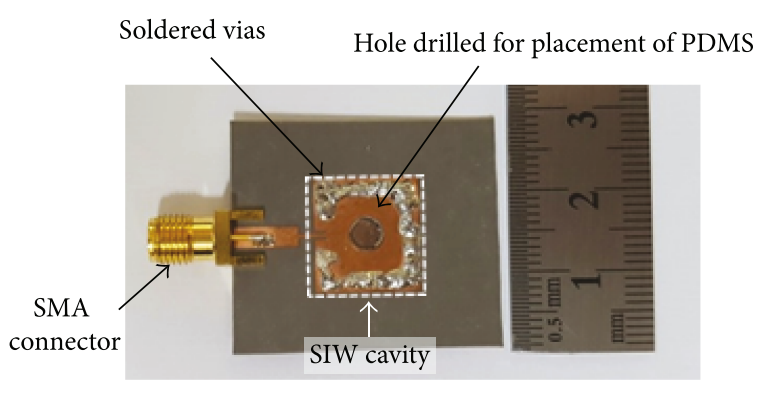

(d)

FIGURE 5: Three-step fabrication process for the SIW cavity resonator proposed as a biosensor. (a) Microstrip patch antenna is visualized. (b) SIW cavity is formed by inserting gold vias in the holes close to the patch boundary, and a big hole is drilled at the center of the patch and substrate to house the PDMS-based microwell. (c) PDMS-based microwell is aligned at the center of SIW cavity, and now, biomaterial is injected through a micropipette and (d) fabricated prototype of the SIW cavity resonator.

detection efficiency, formaldehyde was replaced with PBS. The PBS solution is not only a cell-friendly material but also causes lesser frequency shifts compared to formaldehyde. The frequency shift by the spheroid was more pronounced when a lesser frequency shift was provided by the containing solution. Therefore, the spheroids were more detectable in our system using PBS.

4.4. Fabrication of PDMS Substrate. The cup-shaped microcontainer substrate was made using PDMS (Dow Corning Inc., Midland, MI, USA). The most attractive feature of PDMS-based microfluidics in cell biology is that its size fits the dimensions of cell size [36]. To fabricate the 3D cupshaped microstructure, the first step was to fabricate a thin PDMS film. A 10:1 weight mixture of PDMS prepolymer and curing agent was poured in a petri dish, and the dish was spin coated at $200 \mathrm{rpm}$. The liquid PDMS was spreaded and a thin film $300 \mu \mathrm{m}$ in height was created. Since the sensor is sensitive to the cell location, a thin bottom wall was required. Similarly, a sidewall substrate of $1 \mathrm{~mm}$ thickness was fabricated by spin coating at $50 \mathrm{rpm}$. After spin coating, the two substrates were solidified by baking at $80^{\circ} \mathrm{C}$ for 2 hours. The solidified sidewall substrate was punched using a $1.5 \mathrm{~mm}$ diameter punch and then bonded to the bottom substrate using plasma treatment (product number PDC -32G; Harrick Plasma, Ithaca, NY, USA). The bonded substrates were then punched again with a $2 \mathrm{~mm}$ diameter punch to make a cup-shaped microcontainer. The fabricated prototype of the biosensor is shown in Figure 5(d).

\section{Measurements}

To demonstrate the performance of the fabricated prototype of the biosensor, the S-parameters were measured using the Anritsu MS2038C network analyzer (Anritsu Corporation, Richardson, TX, USA). After full 1-port calibration, S11 was measured for empty microwell-loaded SIW cavity. Then, S11 was recorded for PBS solution and microwell was cleaned to reset the reference frequency (unloaded case). Then, S11 was measured for fibroblast cells, and again, the microwell was cleaned for the next measurement. This sequence was repeated for all the measurements. However, large ripples were observed in the measured S-parameters. The biosensor prototype was completely fabricated in our laboratory, and we speculate that the fabrication inaccuracies contributed ripples in the measurements. For instance, issues might arise because of overetching and bad soldering. In addition, during fabrication, a $4 \mathrm{~mm}$ hole was drilled at the center of the structure to place cup-shaped PDMS. The bottom copper layer of the same size was undesirably peeled off by this drilling process because we cannot control vertical cutting inside a thin substrate by a copper layer margin. Although a patch of copper tape was attached from the bottom side to cover the hole, we cannot consider it an error-free replacement. Despite these inconsistencies, the simulation and measurement results were found to be in good agreement as shown in Figure 6. The resonance frequency with an empty microwell was observed to be $13.65 \mathrm{GHz}$, as shown in Figure 6(a). The resonance frequency switched 


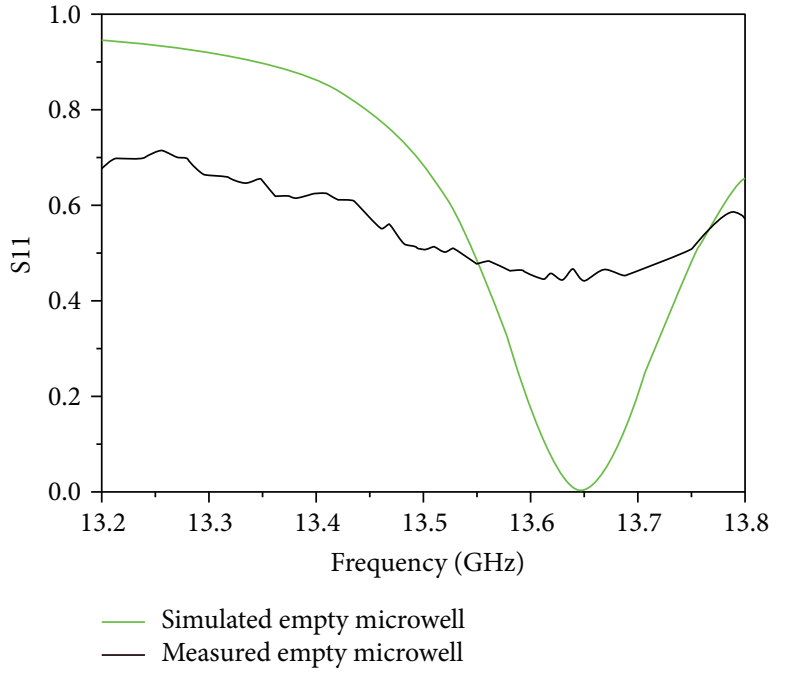

(a)

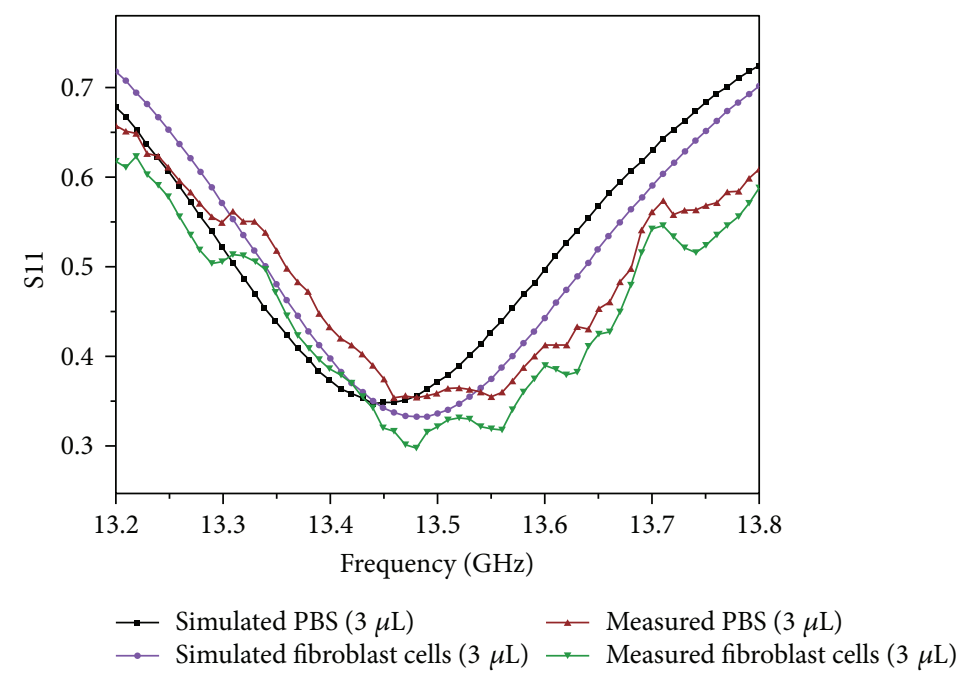

(b)

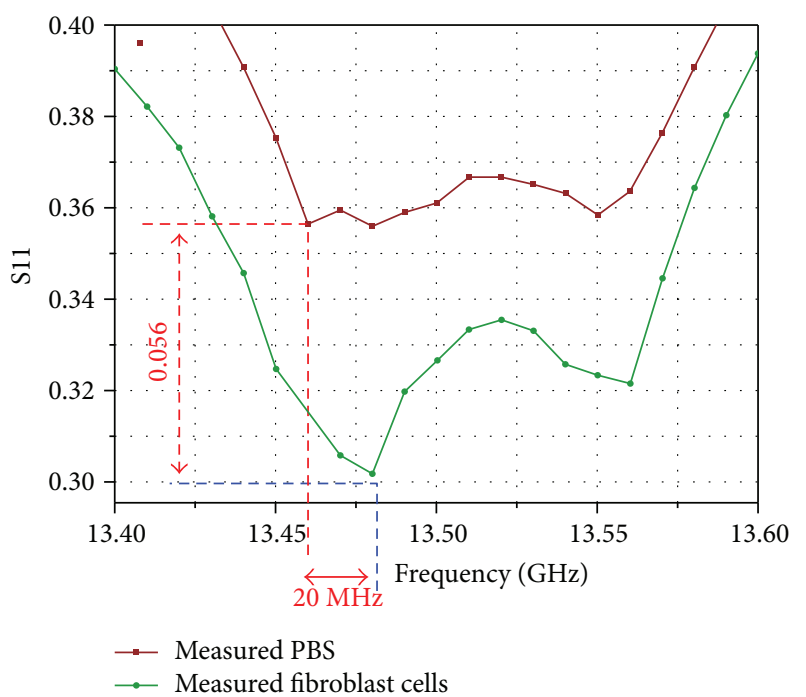

(c)

Figure 6: Simulated and measured return losses (on linear scale) of the proposed biosensor with (a) an empty microwell. (b) Simulated and measured return losses (on linear scale) with PBS solution and FB cells are compared while $3 \mu \mathrm{L}$ fluid was injected in each case. The resonance frequency switched to $13.46 \mathrm{GHz}$ and $13.48 \mathrm{GHz}$, respectively, when PBS solution and FB cells were injected in the microwell. (c) Zoom-in view of (b) to demonstrate the frequency shift and return loss modification after loading FB cells. The S11 (on a linear scale) changes from 0.356 to 0.3 when, respectively, PBS and FB cells are injected.

to $13.46 \mathrm{GHz}$ and $13.48 \mathrm{GHz}$, respectively, when PBS solution and FB cells were injected in the microwell. The simulated and measured return losses of the PBS and FB cells are plotted in Figure 6(b). The zoom-in view presented in Figure 6(c) clearly shows a noticeable shift in the resonance frequency and an amplitude modification when PBS solution is replaced by FB cells. The return loss values (S11 on a linear scale) corresponding to these liquids (PBS and FBs) are 0.30 and 0.356 , respectively, which amounts to $5.6 \%$ modification. The resonance frequency of the FBloaded microwell showed a shift of $170 \mathrm{MHz}$ and $20 \mathrm{MHz}$ relative to an empty and PBS-loaded microwell, respectively. All the measurements are conducted at an ambient temperature of $20^{\circ} \mathrm{C}$ which is accepted as one of the standards, that is, room temperature.
The S11 values (on linear scale) 0.356 and 0.3 with PBS and FB cells correspond to $-8.97 \mathrm{~dB}$ and $-10.45 \mathrm{~dB}$, respectively. S11 contrast $(1.48 \mathrm{~dB})$ and frequency shift $\Delta f=20 \mathrm{MHz}$ can be detected by the commercially available power detection system. For instance, the proposed sensor can be integrated with an Analog Devices CN0387 circuit evaluation board [37] as illustrated in Figure 7. This board is marketed as the "calibration-free return loss measurement system". The difference of two resonance frequencies (peak values) - reference one and the loaded sensor can be measured by the built-in power detector (ADL6010) for the frequency range of $0.5 \mathrm{GHz}$ to $43.5 \mathrm{GHz}$. HMC547LC3 is a single-pole double throw, nonreflective switch with an input frequency ranging from $\mathrm{Dc}$ to $28 \mathrm{GHz}$ with a high-speed switching time of $6 \mathrm{~ns}$. In each position, either of the reverse 


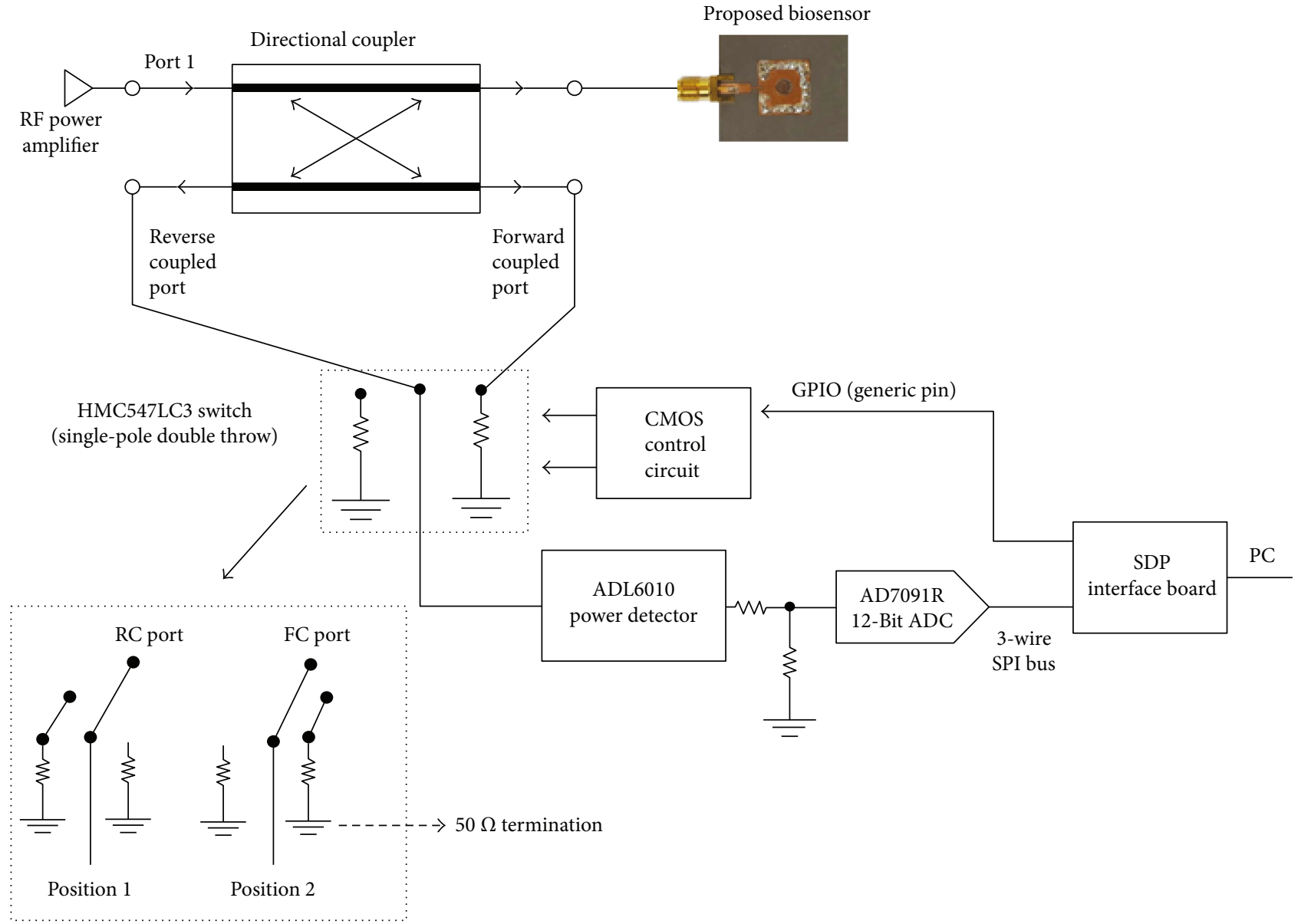

FIgURE 7: Possible system scenario with the block diagram of the CN0387 circuit evaluation board from analog devices (redrawn from [39]).

coupled port or forward coupled port is connected to the power detector (indicated by a solid line) and the other port is $50 \Omega$ terminated. It is reported that a 12 -bit analog/digital converter (ADC) is capable to detect a $1 \mathrm{~dB}$ change in the input power. In addition, although the input is at the bottom end of the detector's input range, high-resolution ADC still can resolve it.

Equation (1) is based on the cavity perturbation model and delicately explains the change in the frequency shift of SIW cavity when liquids of different dielectric constants are injected in the centrally loaded PDMS. Thus, a variation in the effective dielectric constant can switch the resonance frequency [24].

It is shown that as concentrations of FB cells increases, a decrease in relative permittivity of mixture (FB cells and PBS solution) is observed which causes the increase in the resonance frequency (see Figure 8). Despite fluctuations of S11 curves, the response (frequency shift) of our proposed biosensor is a good indicator of FB cell concentrations.

The sensor's repeatability is verified by conducting more than 10 measurements with the same fabricated prototype samples, using the same measurement setup. The measurements of two different media (PBS and FBs) are demonstrated, but for clarity purposes, only three different concentrations are considered to validate the reproducibility. In Figure 9(a), standard deviation of each resonance

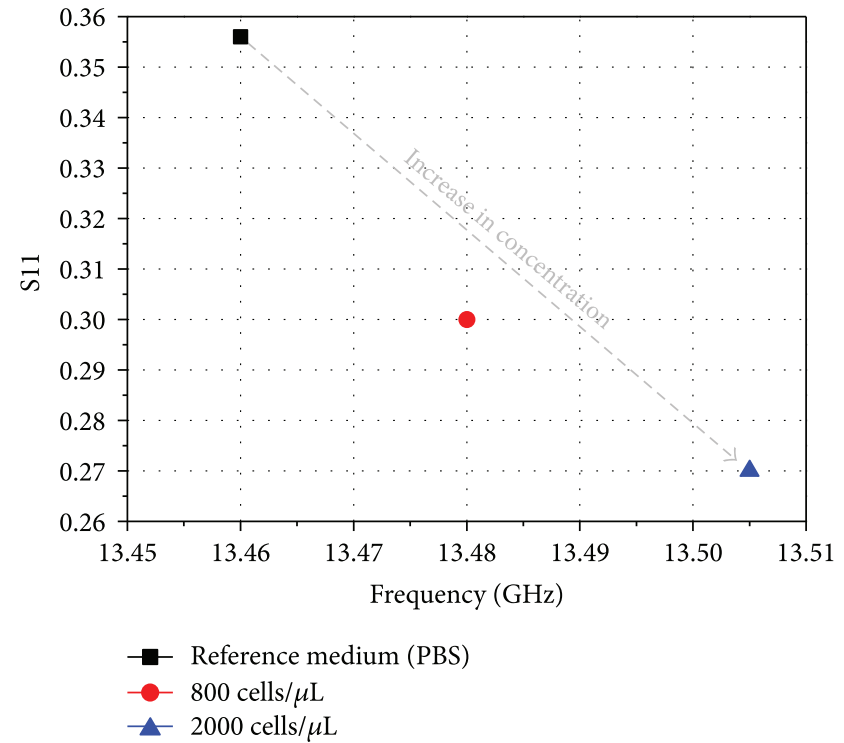

FIGURE 8: Return loss versus resonance frequency at different concentrations of FB cells. Each set of measurements is repeated 10 times. All measurements are done with the same setup and same temperature. 


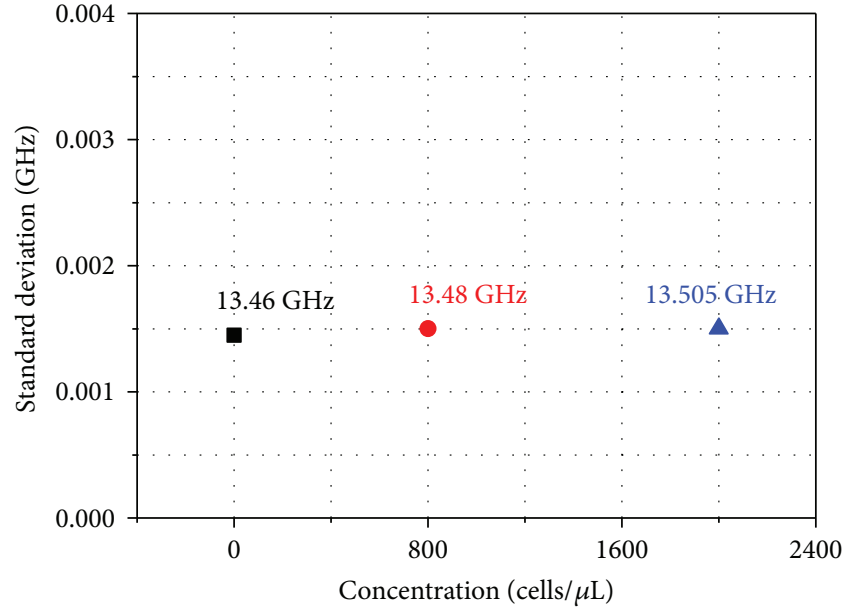

- Std. Dev. of resonant frequency @ Reference medium Std. Dev. of resonant frequency @ 800 FB cells/ $\mu \mathrm{L}$ Std. Dev. of resonant frequency @ 2000 FB cells/ $\mu \mathrm{L}$

(a)

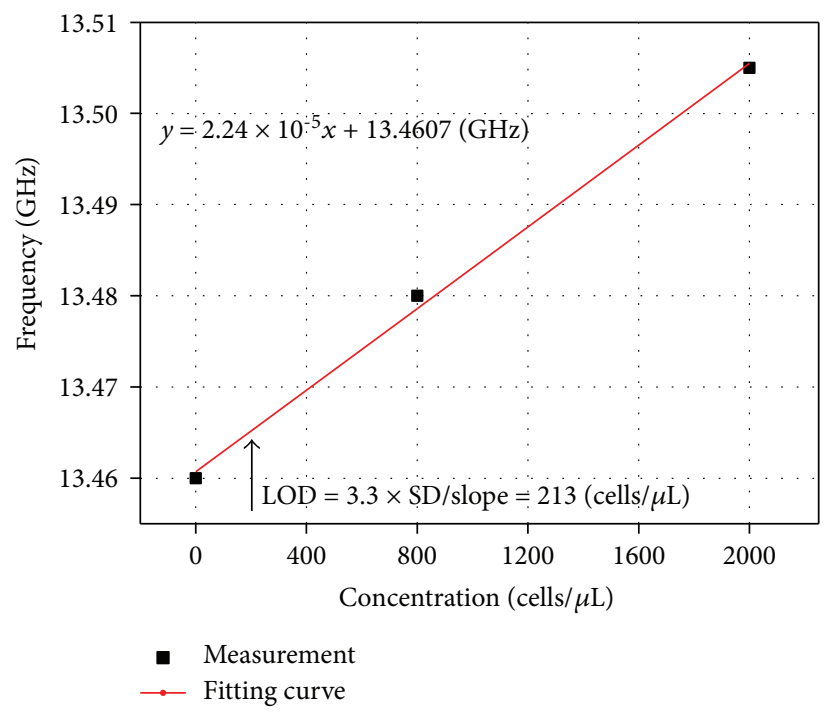

(b)

Figure 9: (a) Standard deviation of each resonance frequency with various concentrations of FB cells at the same temperature and measurement setup. Each set of measurements is repeated 10 times. (b) Resonance frequency corresponding to fibroblast cell concentration (cells $/ \mu \mathrm{L}$ ) is plotted with the fitting curve of $y=2.24 \times 10^{-5} x+13.4607$ in $\mathrm{GHz}$. Limit of detection is calculated using slope of calibration equation and standard deviation of blank response (resonance frequency corresponding to a sample without FB cells).

frequency is plotted while concentrations vary from reference medium with no cells to $800 \mathrm{FB}$ cells $/ \mu \mathrm{L}$ and then $2000 \mathrm{FB}$ cells $/ \mu \mathrm{L}$. All three values of standard deviation show extremely minor variation. It clearly shows that our proposed biosensor is reliable and exhibits repeatability.

The resonance frequency and concentration of FB cells with a linear curve fitting of $y=2.24 \times 10^{-5} x+13.4607$ in $\mathrm{GHz}$ are shown in Figure 9(b). The measurement data follows a linear trend, even though only three sets of measurement data are provided. The limit of detection (LOD) is defined as the lowest quantity/concentration of analyte that can be reliably detected. Reliable detection here means the response should be significantly different from that of a blank/reference. To calculate the limit of detection (analytically), the following well-known formula is utilized [38].

$$
\mathrm{LOD}=3.3 \times\left(\frac{\text { standard deviation }}{\text { slope }}\right) .
$$

The standard deviation (SD) of the reference medium from Figure 9(a) is $1.45 \times 10^{-3} \mathrm{GHz}$, and the slope of calibration equation from Figure 9 (b) is $2.24 \times 10^{-5} \mathrm{GHz} /($ cells $/ \mu \mathrm{L})$. These values are inserted in (4), and the LOD of our proposed biosensor is calculated as 213 cells $/ \mu \mathrm{L}$.

The performance (frequency shift and miniaturization) of our proposed biosensor is compared with those of the state-of-the-art RF bio/chemical sensors, as shown in Table 2. For comparison, selected RF sensors are chosen which resonate above $5 \mathrm{GHz}$. The SIW technology has been used to characterize chemicals. For instance, [20], [36], and [39] are SIW-based chemical sensors to detect single and/or multiple chemicals with frequency shifts of 4.4 MHz, $130 \mathrm{MHz}$, and $110 \mathrm{MHz}$, respectively. Aside from the excellent performance offered by SIW-based designs, small footprints are a significant advantage. Recently, metamaterial elements (SRR, DSRR, and CSRR) have also been utilized to realize chemicals and biosensors. SRR- [34, 35] and DSRR- [33] based biosensor showed frequency shifts in the range of $20 \mathrm{MHz}$ to $60 \mathrm{MHz}$. These designs offer size reduction. An electromagnetic-based resonator along with coating of a selective material has also been proposed [40]. This hybrid RF sensor was proposed to detect ethanol and it showed a $100 \mathrm{MHz}$ shift. The performance of our proposed biosensor (in terms of frequency shift) is comparable/higher to these RF sensors. Metamaterial-based RF sensors are miniaturized; however, in that case, our proposed biosensor shows a higher frequency shift.

MEMS is an advanced fabrication technique which offers massive miniaturization. Our proposed biosensor is also compared with RF MEMS bio/chemical sensors as given in Table 3. These sensors showed frequency shifts in the range of $10-40 \mathrm{MHz}$ [41-44]. Another MEMS-based $\mathrm{RF}$ biosensor is developed to detect glucose levels in human serum, and it showed a frequency shift of $160 \mathrm{MHz}$ [13]. The physical sizes of these MEMS-based RF biosensors are extremely small (generally 1-2 mm by one side). However, a complex manufacturing process as compared to photolithography and bulky and expensive equipment involved in MEMS can be considered as its drawbacks. Our proposed biosensor is more sensitive to all these RF MEMS biosensors, although they exhibit an outstanding miniaturization.

\section{Conclusions}

The development of a miniaturized RF biosensor is an essential step towards future trends: self-diagnosis and point-of- 
TABLE 2: Comparison of our proposed biosensor with other RF bio/chemical sensors.

\begin{tabular}{|c|c|c|c|c|c|c|}
\hline Reference & Target biomaterial/chemical & Sensing element/technology & $\begin{array}{c}\text { Frequency } \\
(\mathrm{GHz})\end{array}$ & $\begin{array}{l}\text { Frequency } \\
\text { shift }(\mathrm{MHz})\end{array}$ & $\begin{array}{l}\text { Physical size } \\
(\mathrm{mm} \times \mathrm{mm})\end{array}$ & Electrical size ${ }^{\dagger}$ \\
\hline [24] & $\begin{array}{l}\text { Acetone, isobutanol, } \\
\text { isopropanol, methanol }\end{array}$ & SIW & 8 & 4.4 & $23 \times 15$ & $0.91 \lambda_{\mathrm{g}} \times 0.6 \lambda_{\mathrm{g}}$ \\
\hline$[40]^{\dagger \dagger}$ & DNA hybridization & DSRR & 12.35 & 20,60 & $20 \times 10$ & $2.56 \lambda_{\mathrm{g}} \times 1.28 \lambda_{\mathrm{g}}$ \\
\hline [39] & Cy3 protein G+ PSA antibody & SRR & 11.35 & 20 & $24 \times 11$ & $2.86 \lambda_{\mathrm{g}} \times 1.31 \lambda_{\mathrm{g}}^{\circ}$ \\
\hline$[38]^{\dagger \dagger \dagger}$ & Cortisol stress hormone & SRR & 10.48 & 20,30 & $20 \times 10$ & $2.1 \lambda_{\mathrm{g}} \times 1.03 \lambda_{\mathrm{g}}$ \\
\hline [41] & $\begin{array}{l}\text { Ethanol, methanol, acetone, } \\
\text { propanol, and so forth }\end{array}$ & SIW & 17.08 & 130 & $35 \times 30$ & $3.03 \lambda_{\mathrm{g}} \times 2.6 \lambda_{\mathrm{g}}$ \\
\hline$[42]$ & Blood glucose & SIW slot antenna & 8.6 & 80 & $80 \times 10$ & $7.33 \lambda_{\mathrm{g}} \times 0.92 \lambda_{\mathrm{g}}$ \\
\hline [43] & Ethanol & $\begin{array}{l}\text { Patch antenna coated } \\
\text { with carbon nanotube }\end{array}$ & 5 & 10,100 & $38.1 \times 11.1$ & $1.32 \lambda_{\mathrm{g}} \times 0.38 \lambda_{\mathrm{g}}$ \\
\hline$[44]$ & Methanol & SIW & 10 & 20,110 & $38 \times 17$ & $1.88 \lambda_{\mathrm{g}} \times 0.84 \lambda_{\mathrm{g}}$ \\
\hline$[45]^{\dagger \dagger \dagger \dagger}$ & Dielectric characterization & SIW & 7.17 & 112 & $63 \times 21$ & $2.23 \lambda_{\mathrm{g}} \times 0.74 \lambda_{\mathrm{g}}$ \\
\hline This work $^{\dagger+\dagger \dagger \dagger}$ & Fibroblast cells & SIW & 13.48 & 20,170 & $33 \times 28$ & $2.26 \lambda_{\mathrm{g}} \times 1.92 \lambda_{\mathrm{g}}{ }^{\circ}$ \\
\hline
\end{tabular}

TABLE 3: Comparison of our proposed biosensor with other RF MEMS bio/chemical sensors.

\begin{tabular}{|c|c|c|c|c|c|c|}
\hline Reference & Target biomaterial/chemical & $\begin{array}{c}\text { Sensing } \\
\text { technology }\end{array}$ & $\begin{array}{c}\text { Frequency } \\
(\mathrm{GHz})\end{array}$ & $\begin{array}{c}\text { Frequency } \\
\text { shift }(\mathrm{MHz})\end{array}$ & $\begin{array}{l}\text { Physical size } \\
(\mathrm{mm} \times \mathrm{mm})\end{array}$ & Electrical size ${ }^{\dagger}$ \\
\hline$[15]$ & Glucose in human serum & MEMS & 9.2 & 90,160 & $2 \times 0.9$ & $0.2 \lambda_{\mathrm{g}} \times 0.1 \lambda_{\mathrm{g}}^{\varphi}$ \\
\hline$[46]$ & Cancerous colorectal cell & MEMS & 5 & 30 & N/A & N/A \\
\hline$[47]$ & Cancerous glial cells & MEMS & 13 & 35 & $15 \times 5$ & $1.27 \lambda_{\mathrm{g}} \times 0.4 \lambda_{\mathrm{g}}^{\varphi \varphi}$ \\
\hline$[48]$ & Glucose in aqueous solution & MEMS & 7.5 & 20 & $1 \times 1$ & N/A \\
\hline [49] & Ethanol, methanol, acetone, ammonia & CMOS-MEMS & 0.12 & 13.2 & $2 \times 0.03$ & N/A \\
\hline This work $^{\dagger \dagger \dagger \dagger \dagger}$ & Fibroblast cells & SIW & 13.48 & 20,170 & $33 \times 28$ & $2.26 \lambda_{\mathrm{g}} \times 1.92 \lambda_{\mathrm{g}}$ \\
\hline
\end{tabular}

${ }^{\varphi}$ Dielectric constant of substrate (gallium arsenide) is assumed $11 \sim 13 .{ }^{\varphi \varphi}$ Dielectric constant of substrate (fused silica) is assumed $3.8 .{ }^{\dagger \dagger \dagger \dagger \dagger} 20 \mathrm{MHz}$ and $170 \mathrm{MHz}$ shifts in resonance frequency are relative to the PBS and empty microwell, respectively. ${ }^{\dagger} \lambda_{\mathrm{g}}$ is the guided wavelength in the structure.

care testing (POCT). The elimination of cumbersome lab testing can save time and investment. For instance, a POCT biosensor can be used for testing human immunodeficiency virus- (HIV-) infected cells of human beings in remote areas. To consider these perspectives, a novel microfluidic biosensor is proposed using a microwave rectangular SIW cavity resonator. The novelty of our proposed biosensor is that the first-time fibroblast cells are being detected using a SIW cavity-based RF biosensor. Our proposed biosensor can be utilized to detect and discriminate biological cells and can provide real-time, accurate, and very fast response. A microwell, which served as a microfluidic container, was integrated on the most sensitive area of the SIW cavity resonator. When fluid was filled in the microwell, the resonance frequency of the cavity resonator shifted because of the variation in effective permittivity. Our proposed device is manufactured using the standard photolithography technique offering very low costs. Its reusability, noncontact nature, and miniaturization are amongst the most attractive features. Its performance was validated through full-wave simulations and S-parameter measurements, and the results showed distinguishable frequency responses when the PBS solution (reference medium) was replaced by FB cells (target biomaterial). With a reasonable analytically measured limit of detection $(213$ cells $/ \mu \mathrm{L})$, it is robust and potentially safe and requires extremely small volumes of liquids (only $3 \mu \mathrm{L}$ ) without any further preparation of biomaterial for testing/analysis.

\section{Conflicts of Interest}

The authors declare that there is no conflict of interest regarding the publication of this paper.

\section{Acknowledgments}

This work was supported by the National Research Foundation of Korea (NRF) grant funded by the Korea government Ministry of Science, ICT and Future Planning (no. 2017R1A2B3003856). 


\section{References}

[1] G. Guarin, M. Hofmann, J. Nehring, R. Weigel, and G. Fischer, "Miniature microwave biosensors: noninvasive applications," IEEE Microwave Magazine, vol. 16, no. 4, pp. 71-86, 2015.

[2] D. Grieshaber, R. Mackenzie, J. Vörös, and E. Reimhult, "Electrochemical biosensors - sensor principles and architectures," Sensors, vol. 8, no. 3, pp. 1400-1458, 2008.

[3] R. Bashir, "BioMEMS: state-of-the-art in detection, opportunities and prospects," Advanced Drug Delivery Reviews, vol. 56, no. 11, pp. 1565-1586, 2004.

[4] F. G. Bănică, Chemical Sensors and Biosensors: Fundamentals and Applications, John Wiley \& Sons, Ltd, Hoboken, NJ USA, 2012.

[5] D. L. Andrews, Photonics: Scientific Foundations, Technology and Applications. Volume IV: Biomedical Photonics, Spectroscopy, and Microscopy, John Wiley \& Sons, Inc., Hoboken, NJ USA, 2015.

[6] T. Chen, S. Li, and H. Sun, "Metamaterials application in sensing,” Sensors, vol. 12, pp. 2742-2765, 2012.

[7] F. Artis, D. Dubuc, J.-J. Fournie, M. Poupot, and K. Grenier, "Microwave dielectric bio-sensing for precise and repetitive living cells suspension analysis," in 2013 European Microwave Conference (EuMC), pp. 468-470, Nuremberg, Germany, October 2013.

[8] J. C. Booth, N. D. Orloff, J. Mateu, M. Janezic, M. Rinehart, and J. A. Beall, "Quantitative permittivity measurements of nanoliter liquid volumes in microfluidic channels to 40 GHz," IEEE Transactions on Instrumentation and Measurement, vol. 59, no. 12, pp. 3279-3288, 2010.

[9] H. J. Lee and J. G. Yook, "Recent research trends of radiofrequency biosensors for biomolecular detection," Biosensors and Bioelectronics, vol. 61, pp. 448-459, 2014.

[10] S. H. Son, H. J. Kim, K. J. Lee et al., "Experimental measurement system for 3-6 GHz microwave breast tomography," Journal of Electromagnetic Engineering and Science, vol. 15, no. 4, pp. 250-257, 2015.

[11] K. Grenier, D. Dubuc, P. E. Poleni et al., "Integrated broadband microwave and microfluidic sensor dedicated to bioengineering," IEEE Transactions on Microwave Theory and Techniques, vol. 57, no. 12, pp. 3246-3253, 2009.

[12] G. J. Yi, W. G. Kang, H. J. Kim, S. I. Jeon, and J. K. Pack, "A prototype system for early-stage breast cancer detection," Journal of Electromagnetic Engineering and Science, vol. 15, no. 3, pp. 158-166, 2015.

[13] F. Artis, T. Chen, T. Chretiennot et al., "Microwaving biological cells: intracellular analysis with microwave dielectric spectroscopy," IEEE Microwave Magazine, vol. 16, no. 4, pp. 87-96, 2015.

[14] Y. Chen, H. Wu, Y. Hong, and H. Lee, "New RF biosensor based on planar LC resonant circuit for human cancer cells characterization," International Journal of Science and Engineering, vol. 4, no. 2, pp. 335-338, 2014.

[15] N. Y. Kim, R. Dhakal, K. K. Adhikari, E. S. Kim, and C. Wang, "A reusable robust radio frequency biosensor using microwave resonator by integrated passive device technology for quantitative detection of glucose level," Biosensors and Bioelectronics, vol. 67, pp. 687-693, 2015.

[16] M. De Ona, S. Melón, P. De La Iglesia, F. Hidalgo, and A. F. Verdugo, "Isolation of influenza virus in human lung embryonated fibroblast cells (MRC-5) from clinical samples," Journal of Clinical Microbiology, vol. 33, no. 7, pp. 19481949, 1995.

[17] B. D. Uhal, C. Ramos, I. Joshi, A. Bifero, A. Pardo, and M. Selman, "Cell size, cell cycle, and $\alpha$-smooth muscle actin expression by primary human lung fibroblasts," American Journal of Physiology-Lung Cellular and Molecular Physiology, vol. 275, no. 5, pp. L998-L1005, 1998.

[18] W. Park and S. Lim, "A low phase-noise microwave oscillator using a substrate integrated waveguide resonator based on complementary split ring resonator," in 2011 Asia-Pacific Microwave Conference Proceedings (APMC), pp. 371-374, Melbourne, VIC, USA, December 2011.

[19] Y. Seo, M. U. Memon, and S. Lim, "Microfluidic eighth-mode substrate-integrated- waveguide antenna for compact ethanol chemical sensor application," IEEE Transactions on Antennas and Propagation, vol. 64, no. 7, pp. 3218-3222, 2016.

[20] T. Yun and S. Lim, "High-Q and miniaturized complementary split ring resonator-loaded substrate integrated waveguide microwave sensor for crack detection in metallic materials," Sensors and Actuators A: Physical, vol. 214, pp. 25-30, 2014.

[21] M. U. Memon and S. Lim, "Reusable EGaIn-injected substrateintegrated-waveguide resonator for wireless sensor applications," Sensors, vol. 15, no. 11, pp. 28563-28573, 2015.

[22] S. Liu, I. Ocket, D. Schreurs, B. Nauwelaers, and W. De-Raedt, "A $60 \mathrm{GHz}$ liquid sensing substrate integrated cavity in LTCC," in 2013 European Microwave Conference (EuMC), pp. 613-615, Nuremberg, Germany, October 2013.

[23] S. Liu, I. Ocket, D. Schreurs, W. De Raedt, and B. Nauwelaers, "A $90 \mathrm{GHz}$ liquid sensing substrate integrated cavity resonator in LTCC for microfluidic sensing applications," in 2014 IEEE MTT-S International Microwave Workshop Series on RF and Wireless Technologies for Biomedical and Healthcare Applications (IMWS-Bio), pp. 6-8, London, UK, December 2014.

[24] K. Saeed, R. D. Pollard, and I. C. Hunter, "Substrate integrated waveguide cavity resonators for complex permittivity characterization of materials," IEEE Transactions on Microwave Theory and Techniques, vol. 56, no. 10, pp. 2340-2347, 2008.

[25] J. D. Barrera and G. H. Huff, "Analysis of a variable SIW resonator enabled by dielectric material perturbations and applications," IEEE Transactions on Microwave Theory and Techniques, vol. 61, no. 1, pp. 225-233, 2013.

[26] N. Haase and A. F. Jacob, "Characterization of biological substances using a substrate integrated microwave nearfield sensor," in 2012 42nd European Microwave Conference (EuMC), pp. 432-435, Amsterdam, Netherlands, November 2012.

[27] M. Bozzi, A. Georgiadis, and K. Wu, "Review of substrateintegrated waveguide circuits and antennas," IET Microwaves, Antennas \& Propagation, vol. 5, no. 8, pp. 909-920, 2011.

[28] T. Meissner and F. J. Wentz, "The complex dielectric constant of pure and sea water from microwave satellite observations," IEEE Transactions on Geoscience and Remote Sensing, vol. 42, no. 9, pp. 1836-1849, 2004.

[29] H. P. Schwan, "Electrical properties of tissues and cell suspensions: mechanisms and models," in Proceedings of the 16th Annual International Conference of the IEEE Engineering in Medicine and Biology Society, 1994. Engineering Advances: New Opportunities for Biomedical Engineers, pp. 70-71, Baltimore, MD, USA, November 1994. 
[30] M. Yvanoff, "LC Sensor for biological tissue characterization," Doctorate Thesis in MICROSYSTEMS ENGINEERING, Rochester Institute of Technology, New York, 2008.

[31] M. Yvanoff and J. Venkataraman, "A feasibility study of tissue characterization using LC sensors," IEEE Transactions on Antennas and Propagation, vol. 57, no. 4, pp. 885-893, 2009.

[32] A. Salim and S. Lim, "Complementary split-ring resonatorloaded microfluidic ethanol chemical sensor," Sensors, vol. 16, no. 11, p. 1802, 2016.

[33] "Data sheet of SMA connector manufactured by GigaLane Co. Ltd.," January 2017, http://www.gigalane.co.kr/board/ bbs/board.php?bo_table=product1\&wr_id=39\&page $=3$.

[34] G.-H. Lee, Y. E. Park, M. Cho, H. Park, and J. Y. Park, "Magnetic force-assisted self-locking metallic bead array for fabrication of diverse concave microwell geometries," Lab on a Chip, vol. 16, no. 18, pp. 3565-3575, 2016.

[35] J. Y. Park, C. M. Hwang, and S. H. Lee, "Ice-lithographic fabrication of concave microwells and a microfluidic network," Biomedical Microdevices, vol. 11, no. 1, pp. 129-133, 2009.

[36] G. M. Whitesides, "The origins and the future of microfluidics," Nature, vol. 442, no. 7101, pp. 368-373, 2006.

[37] E. Nash and K. Barrett, "Calibration-free return loss measurements by analog device," http://www.analog.com/media/en/ technical-documentation/technical-articles/Calibration-FreeReturn-Loss-Measurement.PDF.

[38] H. J. Lee, J. H. Lee, H. S. Moon et al., "A planar split-ring resonator-based microwave biosensor for label-free detection of biomolecules," Sensors and Actuators B: Chemical, vol. 169, pp. 26-31, 2012.

[39] H. J. Lee, J. H. Lee, and H. I. Jung, “A symmetric metamaterial element-based RF biosensor for rapid and label-free detection," Applied Physics Letters, vol. 99, no. 16, pp. 163701163704, 2011.

[40] H. J. Lee, H. S. Lee, K. H. Yoo, and J. G. Yook, "DNA sensing using split-ring resonator alone at microwave regime," Journal of Applied Physics, vol. 108, no. 1, article 014908, 2010.

[41] M. U. Memon and S. Lim, "Millimeter-wave chemical sensor using substrate-integrated-waveguide cavity," Sensors, vol. 16, p. 1829, 2016.

[42] M. Hofmann, T. Fersch, R. Weigel, G. Fischer, and D. Kissinger, "A novel approach to non-invasive blood glucose measurement based on RF transmission," in 2011 IEEE International Workshop on Medical Measurements and Applications Proceedings (MeMeA)no. 3, pp. 39-42, Bari, Italy, May 2011.

[43] A. Mohammadi, A. Ismail, M. Adzir, R. Syamsul, and A. Raja, "Carbon-nanotube-based FR-4 patch antenna as a bio-material sensor," Procedia Engineering, vol. 41, pp. 724728, 2012.

[44] E. Silavwe, N. Somjit, and I. D. Robertson, "A microfluidicintegrated SIW lab-on-substrate sensor for microliter liquid characterization," IEEE Sensors Journal, vol. 16, no. 21, pp. 7628-7635, 2016.

[45] H. Lobato-Morales, A. Corona-Chávez, D. V. B. Murthy, and J. L. Olvera-Cervantes, "Complex permittivity measurements using cavity perturbation technique with substrate integrated waveguide cavities," The Review of Scientific Instruments, vol. 81, no. 6, p. 064704, 2010.
[46] J. Leroy, C. Dalmay, A. Landoulsi et al., "Microfluidic biosensors for microwave dielectric spectroscopy," Sensors and Actuators A: Physical, vol. 229, pp. 172-181, 2015.

[47] C. Dalmay, A. Pothier, P. Blondy, M. Cheray, F. Lalloue, and M. O. Jauberteau, "RF biosensor based on microwave filter for biological cell characterisation," in European Microwave Conference, 2009. EuMC 2009, pp. 41-44, Rome, Italy, October 2009.

[48] T. Chretiennot, D. Dubuc, and K. Grenier, "Microwave-based microfluidic sensor for non-destructive and quantitative glucose monitoring in aqueous solution," Sensors, vol. 16, no. 10, p. 1733, 2016.

[49] M. Yang and C. Dai, "Ethanol microsensors with a readout circuit manufactured using the CMOS-MEMS technique," Sensors, vol. 15, no. 1, pp. 1623-1634, 2015. 


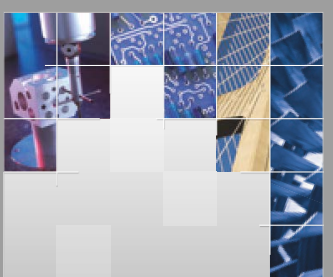

\section{Enfincering}
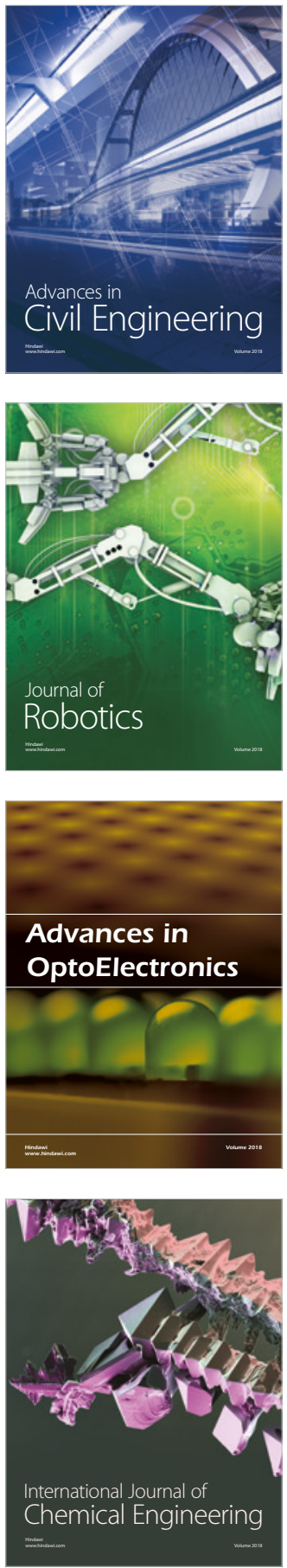

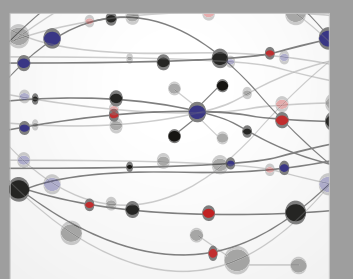

\section{Rotating \\ Machinery}

The Scientific World Journal

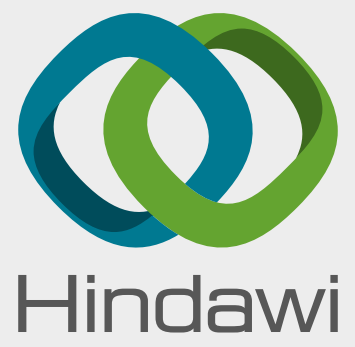

Submit your manuscripts at

www.hindawi.com
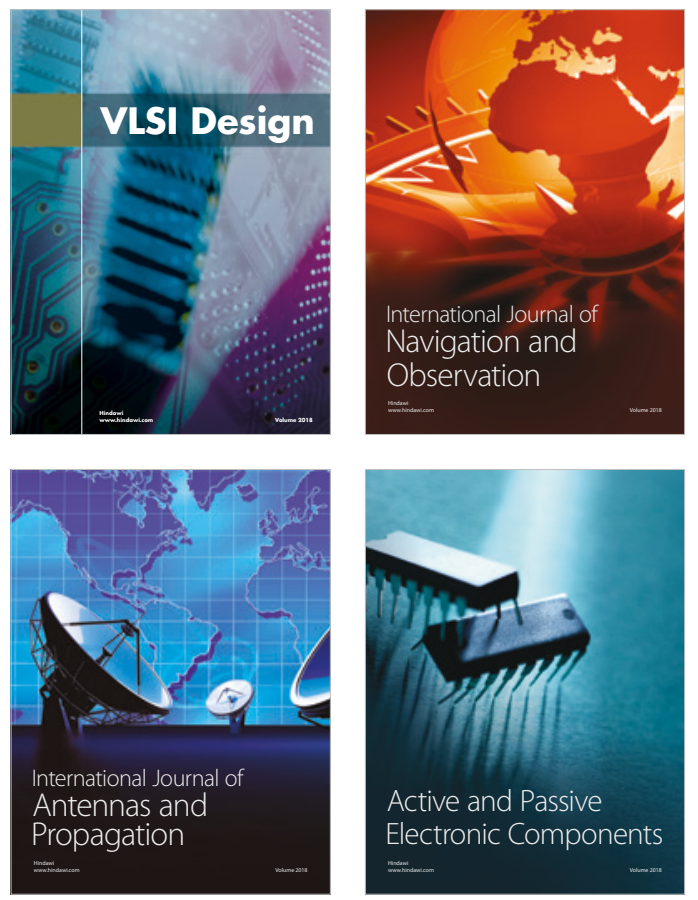
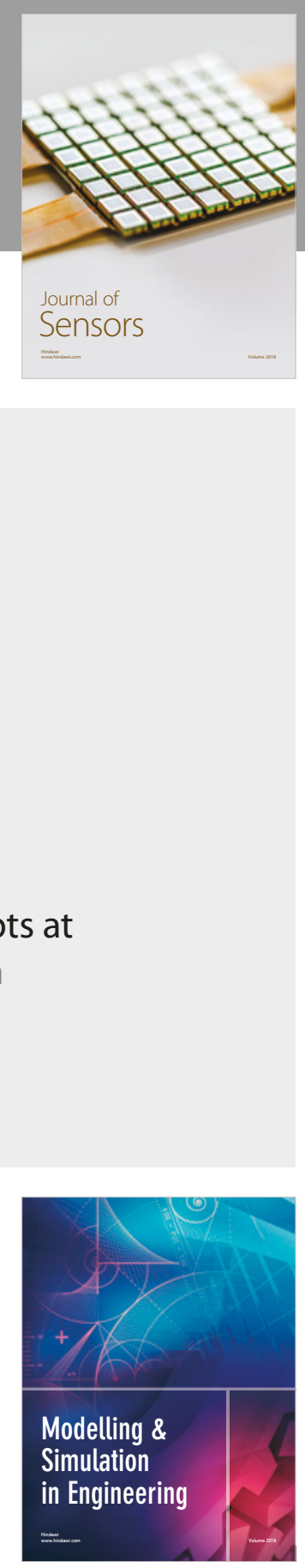

\section{Advances \\ Multimedia}
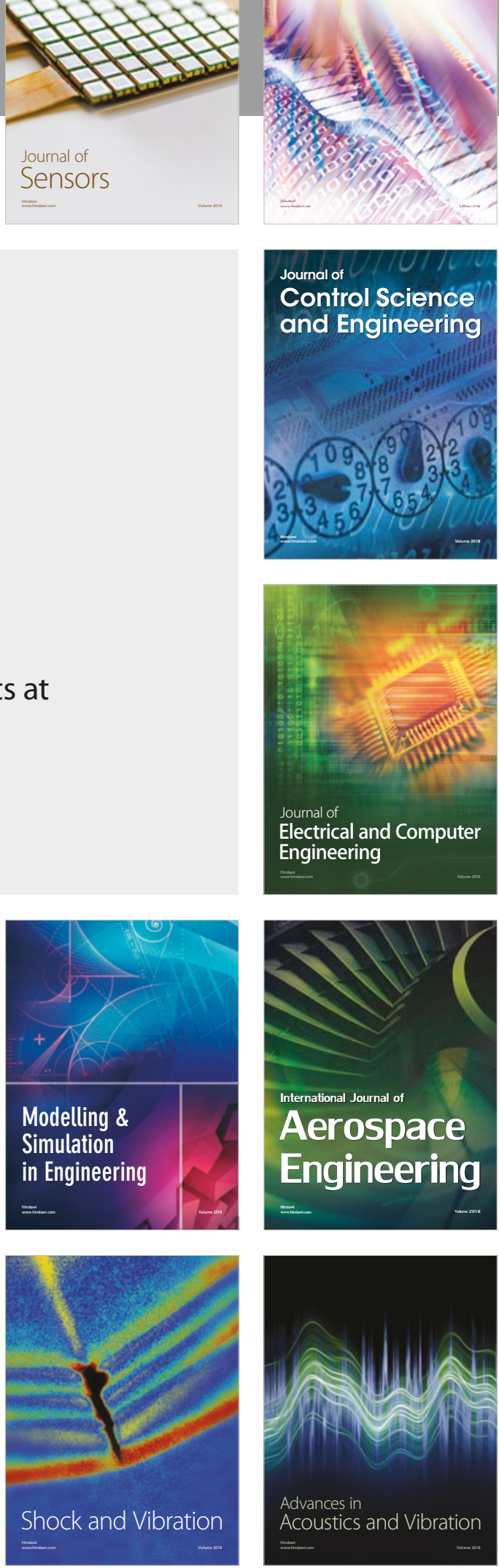